\title{
FATORES AMBIENTAIS NA RESPOSTA FISIOLOGICA E COMPORTAMENTAL DE VACAS LEITEIRAS
}

\author{
ZERO, Raphael Chiarelo ${ }^{1}$ \\ MELLO, Sílvio de Paula²
}

Recebido em: 2015.06 .22

Aprovado em: $2015-12-17$

ISSUE DOI: $10.3738 / 1982.2278 .1508$

\begin{abstract}
RESUMO: O estudo foi desenvolvido na bovinocultura leiteira da Faculdade Dr. Francisco Maeda, localizada no município de Ituverava, SP. Utilizaram-se dez vacas girolandas, multíparas, com peso médio de $450 \mathrm{~kg}$ e produção média diária de 9 litros de leite. O experimento foi conduzido durante a estação de inverno de 2013. Objetivou-se avaliar as condições de estresse térmico, por meio de coletas e análises dos dados de temperatura de bulbo seco, bulbo úmido, temperatura de globo negro, umidade relativa do ar, e posteriormente o cálculo do índice de temperatura de globo e umidade (ITGU). Todos os dados foram coletados no ambiente sombreado e ao sol. Avaliaram-se parâmetros fisiológicos e comportamentais dos animais. Os dados referentes aos fatores ambientais, comportamentais e fisiológicos foram coletados a cada sessenta minutos, no período entre ordenhas, das 9:00 as 14:00 horas. Verificou-se que as condições ambientais referentes à sombra indicaram valores de conforto térmico em quase todos os horários, com exceção das 14:00 horas, com ITGU médio de 77,44, indicando condição de alerta. Os resultados obtidos para o ambiente exposto ao sol apresentaram índices estressantes em todos os horários, indicando situação de alerta e emergência, respectivamente, caracterizando condições de estresse térmico para as vacas em lactação. Grande parte dos parâmetros fisiológicos e comportamentais avaliados não se mostrou compatíveis com os presentes na literatura. Mesmo na estação de inverno, o clima da região avaliada mostrou-se desfavorável para as vacas em lactação, indicando altos valores de ITGU e consequentemente estresse térmico.
\end{abstract}

Palavras-chave: Gado leiteiro. Estresse térmico. Comportamento. Fisiologia.

SUMMARY: This paper was developed in the dairy cattle sector from the university FAFRAM (Faculdade Dr. Francisco Maeda - FAFRAM) located inItuverava, SP. Ten Girolando multiparous cows in intermediate stage of lactation were used, with average weight of $450 \mathrm{~kg}$ and average daily production of 9 liters of milk. The study was conducted during 2013 winter season. The objective of this study was to evaluate the conditions of heat stress, through collection and analysis of these data: the dry and wet bulb temperature, black globe temperature, airrelative humidity, and then calculating the black globe humidity index (BGHI). All data were collected under shade and sun. Physiological and behavioral parameters of lactating cows were also assessed. The data relating to environmental, behavioral and physiological factors were collected every sixty minutes in the period between milking, from 9:00 am to $2: 00 \mathrm{pm}$, in the shade and in the sun. From the analysis of the data and the averages of all parameters, we have come to the results. It was noticed that the environmental conditions on the shade locations indicated values of thermal comfort in almost all times that were evaluated, but the results obtained for the unshaded environment presented themselves very high at all times, indicating a state of alert and emergency, confirming the thermal stress for lactating cows. Vast majority of physiological and behavioral parameters evaluated was not compatible with the ones from the literature. Even though in the winter season, the climate of the city Ituverava proves unfavorable for lactating cows, indicating high values of BGHI and consequently causing heat stress in the animals.

Keywords: Dairy cattle. Thermal stress. Behavior. Physiology

\footnotetext{
${ }^{1}$ Bovinocultura leiteira, Medicina veterinária - Faculdade Dr. Francisco Maeda - Ituverava

${ }^{2}$ Prof. Titular FE/FAFRAM. Dr. em Genética e Evolução.
} 


\section{INTRODUÇÃO}

O Brasil possui atualmente um rebanho leiteiro com aproximadamente 40.175.088 cabeças de vacas leiteiras. Só em 2013 a produção leiteira estimada foi de 25.758 .052 litros, demonstrando um crescimento significativo em relação aos anos anteriores, observando-se um constante aumento na produção de leite brasileira (ANUALPEC, 2014).

Segundo Mellace (2009) cerca de dois terços do território brasileiro situa-se na faixa tropical do planeta, havendo predominância de altas temperaturas e exposição à radiação. As temperaturas médias anuais ficam acima de $20^{\circ} \mathrm{C}$, com máximas podendo ultrapassar a faixa $\operatorname{dos} 38^{\circ} \mathrm{C}$ (TITTO, 1998). O clima é um dos componentes ambientais que exerce efeito mais pronunciado sobre o bem-estar animal refletindo negativamente na produção e produtividade. Representa um conjunto de fenômenos meteorológicos, de natureza complexa e que, atuando isolada ou conjuntamente, constitui-se em componente decisivo no comportamento animal (PEREIRA, 2005).

Segundo Silva (2000), vários são os efeitos do clima tropical e subtropical, sobre os sistemas dos animais domésticos, podendo influenciar negativamente quando em condições de estresse térmico na reprodução, crescimento e desenvolvimento, na ingestão de alimentos e água, e influência negativamente a produção de leite.

Vacas em lactação, assim como todos os animais de sangue quente, são homeotérmicos, ou seja, controlam dentro de certos limites sua temperatura corporal interna. Mas para que isso ocorra de maneira eficiente, é preciso que o ambiente esteja em condições ideais de conforto térmico, para que, as trocas térmicas possam ocorrer sem que haja perdas nos processos reprodutivos e produtivos. É sabido que o bovino mantém sua temperatura interna constante independente das condições ambientais, mas o recomendável é que o ambiente esteja em boas condições térmicas, se isso não ocorrer os animais precisarão gastar uma maior quantidade de energia para que a homeostase ocorra, sendo esta energia retirada principalmente da produção de leite, no caso desta categoria animal (NUPEA, 2014).

Condições de estresse térmico, causadas pelas altas temperaturas e umidade relativa do ar, resultam em uma diminuição da produção de leite, e quando em condições mais severas pode levar a morte de animais. Nesse sentido, o objetivo do presente trabalho foi avaliar as condições de conforto térmico e relacioná-las com parâmetros fisiológicos e comportamentais dos animais avaliados.

\section{MATERIAL E MÉTODO}


O estudo foi desenvolvido no Setor de Bovinocultura Leiteira da Faculdade Dr. Francisco Maeda - FAFRAM Ituverava-SP, localizada no Sítio das Acácias, com $20^{\circ} 2030$ de latitude Sul, 47\%4730 de longitude Oeste e altitude média de 690 metros. O clima da região é classificado como tropical úmido e a temperatura média anual de $23,3{ }^{\circ} \mathrm{C}$. O experimento ocorreu durante a estação de inverno (junho a setembro de 2013), onde foram coletadas informações referentes a condições climáticas, fisiológicas e comportamentais, em dias não consecutivos, totalizando sete dias.

Em cada dia realizou-se seis visualizações, as quais foram aferidas a cada sessenta minutos no período entre- ordenhas, sendo das nove às quatorze horas. Utilizou-se 10 vacas girolandas, multíparas, na fase intermediária de lactação, com peso médio de $450 \mathrm{~kg}$ e produção média de $9 \mathrm{~kg} /$ leite/dia, todas permaneceram em piquete único com disposição de cocho com silagem de milho, cocho com sal mineral, bebedouro, sombra natural e pastagem (ad libitum).

As variáveis meteorológicas aferidas do ambiente sombreado foram temperatura de bulbo seco (Tbs), temperatura de bulbo úmido (Tbu) e umidade relativa do ar (UR), com o auxílio de termohigrômetro da marca INCO THERM ${ }^{\circledR}$. A temperatura de globo negro (Tgn) foi adquirida a partir de termômetro de globo negro, ambos devidamente instalados na única sombra natural, provinda da árvore mangifera indica, conhecida popularmente como mangueira, conforme ilustrado na figura 1 .

Figura 1: Imagem fotográfica do Termohigrometro de bulbo seco e bulbo úmido, e globo negro instalados na sombra, no local do estudo, Ituverava-SP, 2014.

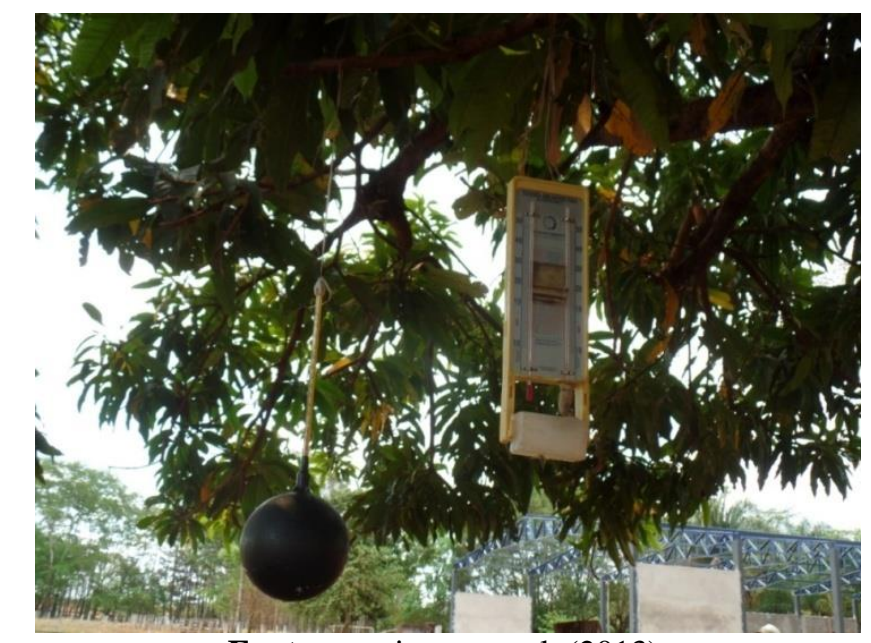

Fonte: arquivo pessoal, (2013).

Os dados referentes ao ambiente desprovido de sombra, ou seja, no sol, foram adquiridas através de termômetros de bulbo seco e bulbo úmido, pertencentes à estação meteorológicas da 
faculdade, situada a 50 metros do local do estudo, e por termômetro de globo negro, devidamente instalado nas dependências da estação.

Foi realizado o cálculo do Índice de Temperatura de Globo e Umidade (ITGU) na sombra e no sol, este índice indica valores reais das condições de estresse térmico ambiental, levando em conta os efeitos da ventilação e da radiação solar na sensação térmica dos animais. Os cálculos foram realizados a partir das seguintes equações:

$\mathrm{ITGU}=\mathrm{Tgn}+0,36 \mathrm{Tpo}+41,5$

em que,

Tgn - temperatura de globo negro, $\mathrm{C}^{\mathbf{o}}$.

Tpo - temperatura do ponto de orvalho.

Os parâmetros fisiológicos mensurados foram frequência respiratória (FR) e temperatura média do pelame (TP). A FR foi obtida através da observação visual e contagem dos movimentos do flanco durante 15 segundos e corrigidas para um minuto. A temperatura média do pelame foi adquirida através da aferição direta utilizando-se termômetro infravermelho digital em três locais distintos do animal, sendo pescoço, costelas e garupa, (figura 2). Os parâmetros comportamentais observados foram ócio em pé, ócio deitada, andando, pastando, ruminando em pé, ruminando deitada, comendo no cocho, hidratando, mineralizando, e localização.

Os resultados obtidos das variáveis estudadas foram contrastados com a literatura e serviram para verificar se os animais estão em condições de conforto ou estresse térmico.

Figura 2: Imagem fotográfica representando o local de coleta de temperatura do pelame de vacas leiteiras, a partir do termômetro de infravermelho direcionado no pescoço, costelas e garupa do animal. Ituverava-SP, 2014.

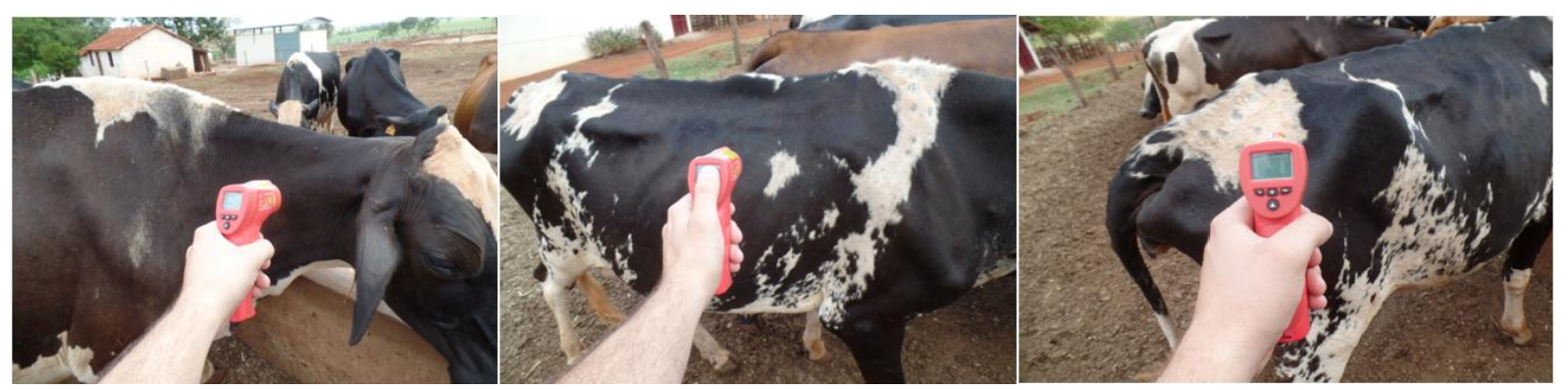

Fonte: arquivo pessoal, (2013).

\section{RESULTADO E DISCUSSÃO}


Os valores médios das variáveis ambientais, temperatura do pelame e do índice de temperatura de globo e umidade (ITGU), nas localizações sol e sombra, estão descritos na tabela 1.

Tabela 1. Valores médios das temperaturas de pelame, bulbo seco, bulbo úmido, globo negro, umidade relativa e Índice de temperatura de globo e umidade (ITGU), nas localizações sol e sombra. Ituverava-SP, 2014.

\begin{tabular}{|c|c|c|c|c|c|c|}
\hline \multicolumn{7}{|c|}{ Temperatura do pelame $\left({ }^{\circ} \mathrm{C}\right)$} \\
\hline Horas & 9:00 & $10: 00$ & 11:00 & 12:00 & 13:00 & 14:00 \\
\hline Sol & 34,88 & 39,18 & 38,26 & 37,44 & 38,73 & 38,04 \\
\hline Sombra & 33,32 & 31,38 & 34,27 & 32,97 & 33,42 & 33,03 \\
\hline \multicolumn{7}{|c|}{ Temperatura de bulbo seco $\left({ }^{\circ} \mathrm{C}\right)$} \\
\hline Horas & 9:00 & 10:00 & 11:00 & 12:00 & 13:00 & 14:00 \\
\hline Sol & 21,77 & 24,58 & 26,50 & 27,54 & 30,25 & 29,02 \\
\hline Sombra & 20,90 & 24,11 & 25,86 & 26,92 & 27,88 & 28,08 \\
\hline \multicolumn{7}{|c|}{ Temperatura de bulbo úmido $\left({ }^{\circ} \mathrm{C}\right)$} \\
\hline Horas & 9:00 & 10:00 & 11:00 & 12:00 & 13:00 & 14:00 \\
\hline Sol & 17,45 & 19,78 & 21,53 & 21,94 & 22,98 & 23,64 \\
\hline Sombra & 14,98 & 16,58 & 16,93 & 17,54 & 17,71 & 18,17 \\
\hline \multicolumn{7}{|c|}{ Temperatura de globo negro $\left({ }^{\circ} \mathrm{C}\right)$} \\
\hline Horas & 9:00 & 10:00 & 11:00 & 12:00 & 13:00 & 14:00 \\
\hline Sol & 33,47 & 37,48 & 39,46 & 41,07 & 39,25 & 38,30 \\
\hline Sombra & 21,68 & 24,68 & 25,60 & 28,21 & 29,41 & 32,15 \\
\hline \multicolumn{7}{|c|}{ Umidade relativa (\%) } \\
\hline Horas & 9:00 & 10:00 & 11:00 & 12:00 & 13:00 & 14:00 \\
\hline Sol & 64,37 & 62,98 & 63,60 & 60,40 & 54,95 & 63,50 \\
\hline Sombra & 53,01 & 44,31 & 38,05 & 36,81 & 33,18 & 36,14 \\
\hline \multicolumn{7}{|c|}{ Índice de Temperatura de Globo e Umidade (ITGU) } \\
\hline Horas & 9:00 & 10:00 & 11:00 & 12:00 & 13:00 & 14:00 \\
\hline Sol & 80,14 & 85,16 & 87,83 & 89,42 & 87,50 & 87,28 \\
\hline Sombra & 66,71 & $\mathbf{7 0 , 3 3}$ & 70,66 & 73,71 & 74,33 & $\mathbf{7 7 , 4 8}$ \\
\hline
\end{tabular}

Fonte: Elaborado pelo autor (2014).

A temperatura do pelame sofre variações dependentes das condições climáticas ambientais, sendo influenciada pela temperatura e umidade relativa do ar, velocidade dos ventos e pelas condições fisiológicas de cada individuo (FERREIRA et al., 2006). Conforme mencionado por Martello (2006), valores de temperatura do pelame entre 31,6 a $34,7^{\circ} \mathrm{C}$ não indicaram sofrimento por estresse térmico em ambientes climatizados. Medeiros e Vieira (1997) relataram que há aquecimento da pele devido à dilatação dos vasos sanguíneos superficiais como consequência da exposição a temperaturas ambientais acima dos limites críticos, tal dilatação, porém pode auxiliar no resfriamento do corpo pelo mecanismo de condução do calor corpóreo até a pele, e de radiação da mesma para o ambiente. 
As médias das temperaturas de pelame estão descritas na tabela 1, onde os valores encontrados para os animais que se encontravam na sombra, não ultrapassaram os propostos por Martello (2006), não caracterizando condições de estresse térmico em nenhum dos horários observados, porém as médias de temperatura de pelame dos animais expostos ao sol apresentaram-se acima dos valores de referencia, principalmente as dez e treze horas, com médias de 39,18 e $38,73^{\circ} \mathrm{C}$, respectivamente, caracterizando uma condição não compatível de conforto térmico para bovinos.

Conforme mencionada por Nããs (1989), a zona termoneutra (ZT) para vacas em lactação, é observada como uma faixa limitada de temperaturas mínimas e máximas consideradas ótimas para a fisiologia e produção, onde a manutenção da homeotermia ocorre com mínimas mobilizações dos mecanismos de termorregulação. Esta faixa de temperatura ideal para conforto térmico das vacas em lactação situa-se entre 4 a $24^{\circ} \mathrm{C}$.

As temperaturas de bulbo seco na sombra indicaram valores acima da zona termoneutra (ZT) para bovinos em lactação, com exceção ao horário das nove horas da manhã, que obteve temperaturas médias inferiores a $24^{\circ} \mathrm{C}$, Pereira (2005) cita um limite Maximo de tolerância de até $30^{\circ} \mathrm{C}$ para vacas em lactação, neste sentido, o único horário observado que ultrapassou este limite foi exclusivamente as 13:00 horas, com temperatura média de $30,25^{\circ} \mathrm{C}$.

Segundo Starling et al (2002) a baixa umidade relativa do ar causa desidratação e irritação da pele e mucosas, já uma alta umidade relativa do ar desencadeia problemas relacionados a evaporação do suor e dificuldades na termorregulação.

Os resultados considerados normais permanecem entre 50 e $70 \%$ de umidade relativa do ar, Tinôco (2001). Os valores mensurados na sombra nos seguintes horarios 10:00, 11:00, 12:00, 13:00 e 14:00, apresentaram-se abaixo dos valores referidos, variando entre 33,18 a 44,31\%. Em todos os horários referentes ao sol, e as 9:00 horas na localização sombra, as médias encontraram-se dentro dos limites considerados normais.

Com relação ao índice de temperatura de globo e umidade (ITGU) valores até 74 definem condição de conforto térmico, entre 75 e 78 a situação é de alerta, de 79 a 84 caracterizam perigo e acima deste, depara-se com situação de emergência e alto índice de estresse térmico, segundo National Weather Service (EUA), (apud Baêta, 1997).

Os valores médios obtidos e citados na tabela 1 indicam que o ambiente sombreado encontrava-se em condições de conforto térmico nos horários: 9:00, 10:00, 11:00, 12:00 e 13:00 horas. Já as 14:00 horas o ambiente encontrava-se em condições de alerta, com resultados médios de 77,44 . 
Os valores médios de ITGU no sol apresentaram índices mais elevados em relação à sombra, onde os valores encontrados indicaram situação de estresse térmico em todos os horários. Os valores mencionados na tabela 1 apontam que as 9:00 horas o ambiente encontrava-se em situação de perigo, com valores acima dos propostos por Baêta (1997) Os resultados obtidos às 10:00, 11:00, 12:00, 13:00 e 14:00 horas apontaram condições de emergência com valores partindo de 85,16 as dez horas da manhã até 89,42 ao meio dia.

Tabela 2. Valores médios das frequências respiratórias dos animais avaliados a cada 60 minutos no período experimental. Ituverava-SP, 2014.

\begin{tabular}{lllllll}
\hline Frequência respiratória (Mov/Min) & & & & \\
\cline { 2 - 7 } Horas & $9: 00$ & $10: 00$ & $11: 00$ & $12: 00$ & $13: 00$ & $14: 00$ \\
Sol & 38,67 & 36,87 & 43,82 & $\mathbf{5 6 , 3 6}$ & $\mathbf{5 1 , 1 6}$ & $\mathbf{4 4 , 4 8}$ \\
Sombra & $\mathbf{3 4 , 0 0}$ & $\mathbf{2 8 , 0 0}$ & $\mathbf{2 5 , 5 0}$ & $\mathbf{3 3 , 8 7}$ & $\mathbf{3 6 , 5 7}$ & $\mathbf{3 7 , 6 5}$ \\
\hline
\end{tabular}

Fonte: Elaborado pelo autor (2014).

Os valores referentes às médias das frequências respiratórias dos bovinos avaliados estão expressos na tabela 2, onde se notou que em todos os horários e nas duas localizações, sol e sombra, as médias encontraram-se dentro dos valores considerados normais para vacas em lactação, estando entre 18 e 60 movimentos por minuto, conforme descrito por Hahn et al. (1997). Porém observou-se que o crescimento destes valores acompanharam o aumento dos índices de conforto térmico, principalmente nos horários das 12:00 e 13:00 horas no sol, onde os valores crescentes da frequência respiratória, seguiram o aumento dos valores de ITGU nestes horários (tabela 1), que foram 89,42 e 87,50 , respectivamente. Tal fato pode ser justificado levando em conta que a alteração da frequência respiratória atua como um mecanismo de adaptação dos animais ao estresse térmico (Nããs, 1989).

Segundo Peters et al., (2007) a primeira resposta biológica ao estresse térmico é a comportamental, onde os animais evitam o agente estressor, sendo assim, os bovinos utilizam uma variedade de estratégias comportamentais, quando expostos a condições de estresse calórico, tais como procura por sombra, orientação ao sol e aumento da ingestão de água (BLACKSHAW; BLACKSHAW, 1994).

As médias dos parâmetros comportamentais avaliados foram descritos na tabela 3, onde se observou que às nove horas da manhã, $87,14 \%$ dos animais optaram por se alimentar no cocho. Observando o resultado médio da temperatura de bulbo seco (tabela 1), nota-se que este mesmo comportamento foi diminuindo conforme o aumento da temperatura ao decorrer das horas.

Tabela 3. Valores percentuais dos comportamentos das vacas leiteiras observados por hora, no período entre ordenhas. Ituverava-SP, 2014. 


\section{(\%) Comportamentos}

\begin{tabular}{lllllll}
\hline Hora & $\mathbf{9 : 0 0}$ & $\mathbf{1 0 : 0 0}$ & $\mathbf{1 1 : 0 0}$ & $\mathbf{1 2 : 0 0}$ & $\mathbf{1 3 : 0 0}$ & $\mathbf{1 4 : 0 0}$ \\
\cline { 1 - 5 } Comendo cocho & $\mathbf{8 7 , 1 4}$ & $\mathbf{4 1 , 6 7}$ & $\mathbf{2 6 , 6 7}$ & $\mathbf{2 7 , 1 4}$ & $\mathbf{1 8 , 3 3}$ & $\mathbf{1 5 , 7 1}$ \\
Ócio deitada & $\mathbf{1 , 4 3}$ & $\mathbf{2 1 , 6 7}$ & $\mathbf{2 1 , 6 7}$ & $\mathbf{8 , 5 7}$ & $\mathbf{1 1 , 6 7}$ & $\mathbf{1 7 , 1 4}$ \\
Ócio em pé & $\mathbf{5 , 7 1}$ & $\mathbf{1 6 , 6 7}$ & $\mathbf{1 8 , 3 3}$ & $\mathbf{1 5 , 7 1}$ & $\mathbf{6 , 6 7}$ & $\mathbf{7 , 1 4}$ \\
Pastejando & $\mathbf{5 , 7 1}$ & $\mathbf{1 5 , 0 0}$ & $\mathbf{1 6 , 6 7}$ & $\mathbf{2 2 , 8 6}$ & $\mathbf{3 8 , 3 3}$ & $\mathbf{1 8 , 5 7}$ \\
Ruminando deitada & - & $\mathbf{5 , 0 0}$ & $\mathbf{1 3 , 3 3}$ & $\mathbf{1 0 , 0 0}$ & $\mathbf{1 5 , 0 0}$ & $\mathbf{3 1 , 4 3}$ \\
Ruminando em pé & - & - & - & $\mathbf{1 0 , 0 0}$ & $\mathbf{1 0 , 0 0}$ & $\mathbf{1 0 , 0 0}$ \\
Andando & - & - & - & $\mathbf{1 , 4 3}$ & - & - \\
Bebendo água & - & - & $\mathbf{1 , 6 7}$ & $\mathbf{4 , 2 9}$ & - & - \\
\hline
\end{tabular}

Fonte: Elaborado pelo autor (2014).

As dez e onze horas houve um aumento significativo na quantidade de animais em ócio em pé e ócio deitado, onde as temperaturas ambientais encontravam-se entre 24 e $26,50^{\circ} \mathrm{C}$ (tabela 1). Segundo Damasceno et al. (1999) os animais permanecem mais tempo em ócio nos períodos de maior radiação, o mesmo foi observado as 11:00 horas, onde 40\% dos animais encontravam-se nesta situação. Os valores médios de radiação neste horário atingiram o segundo maior índice observado no estudo, chegando à temperatura média de globo negro no sol de $39,46^{\circ} \mathrm{C}$ (tabela 1 ).

Com relação e ingestão de água, as observações indicaram baixos índices percentuais de visitas ao bebedouro, com valores entre 1,67 a 4,29\% às 11:00 e 12:00 horas respectivamente. Tal fato concorda com os resultados encontrados por Perissinotto et al.; (2003), mostrando que o numero de visitas ao bebedouro tendeu a acompanhar o aumento da temperatura do globo negro (tabela 1).

Pires (1998) cita que em condições ambientais estressantes, os animais tendem a gastar maior parte do dia, procurando por água para tentar amenizar o efeito adverso do ambiente, o contrario foi observado no presente estudo, onde nota-se que os animais passam maior parte do seu tempo, mesmo em condições estressantes, se alimentando.

Os mesmos resultados ainda contradizem a versão de Blackshaw e Blackshaw (1994), que bovinos quando em situações de estresse térmico, utilizam uma variedade de estratégias comportamentais como a procura por sombra, orientação ao sol e aumento da ingestão de água.

Valores elevados do comportamento ruminando deitada, foram observados a partir das 13:00 horas, com 15\% dos animais e o dobro as 14:00 horas. Já para o comportamento ruminando em pé valores de $10 \%$ foram observados a partir das 12:00 horas e perdurando-se até as 14:00 horas. $\mathrm{O}$ ato de ruminar é uma atividade onde ocorre um estado de relaxamento dos bovinos (ALBRIGHT, 1993), onde as vacas permanecem relaxadas e quietas, com preferência pela sombra.

Em todos os horários foram observados animais pastejando, porém nas horas $12 \mathrm{~h}, 13 \mathrm{~h}$ e 14h horas, a frequência mostrou-se relativamente maior, com valores de 22,86, 38,33 e 18,57 \%, 
respectivamente. Notou-se que mesmo sendo os horários mais quentes do dia, grande parcela dos animais optaram pelo pastejo, discordando com resultados observados pelos autores (PIRES et al., 1999; PORTUGAL, 2000) que mencionaram que o tempo de pastejo correlaciona-se negativamente com a temperatura ambiente.

Normalmente o maior percentual das vacas optam por se alimentarem nos locais sombreados durante as horas mais quentes do dia (PERERA et al., 1986), porem devido as condições presentes no local do estudo, não foi possível observar este tipo de comportamento, pois o cocho e a pastagem se encontraram relativamente distantes dos locais sombreados.

\section{CONCLUSÃO}

Os valores obtidos mostraram que na estação de inverno, a região avaliada apresenta condições ambientais desfavoráveis para vacas em lactação devido ao alto nível de estresse térmico, e que nestas condições grande parte dos parâmetros fisiológicos e comportamentais não condiz com os resultados presentes na literatura.

\section{REFERÊNCIAS}

ALBRIGHT, J.L. Feeding Behaviour of dairy cattle. Journal of Dairy Science, v.76, p. 485-498, 1993.

ANUALPEC 2014: Anuário da pecuária brasileira. 21 ed. São Paulo: informa economics, 2014, p. 192-193.

BAÊTA, F.C.; SOUZA, C.F. Ambiência em edificações rurais: conforto animal. Viçosa: UFV, 1997. p. 246.

BLACKSHAW, J.K.; BLACKSHAW, A.W. Heat stress in cattle and the effect of shade on production and behavior: a review. Australian Journal of Experimental Agriculture. Colingwood, v.34, p.285-295, 1994.

DAMASCENO, J. C.; BACCARI JR E TARGA, L.A. Respostas comportamentais de vacas holandesas, com acesso à sombra constante ou limitada. Pesquisa agropecuária brasileira. Brasília, v.34, n.4, p. 709-715, abr. 1999.

FERREIRA, F.et al. Parâmetros fisiológicos de bovinos cruzados submetidos ao estresse calórico. Arquivo Brasileiro de Medicina Veterinaria e Zootecnia, Belo Horizonte, v.58, p.732-738, 2006. 
HAHN, G.L.; MADER, T.L. Heat waves in relation on thermoregulation, feeding behavior, and mortality of feedlot cattle. In : International Livestock 42 Environment Symposium, 5., Mennesota, 1997. Proceedings. ST. Joseph: ASAE,1997. p.125-129.

MARTELLO, L.S. Interação animal ambiente: efeito do ambiente climatic sobre as respostas fisiológicas e produtivas de vacas holandesas em free-stall. 2006. 106 p. Tese (Doutorado em Zootecnia)- Faculdade de Engenharia e Ciência dos Alimentos, Universidade de São Paulo, Pirassununga, 2006.

MEDEIROS, L. F. D.; VIEIRA, D. H. Bioclimatologia animal. 1997. Disponível em: http://www. iz.ufrj.br/zootecnia_draa/biblioteca/Fernando/ apostila\%20I.pdf. Acesso em: 12 nov. 2013.

MELLACE, E.M. Eficiência da área de sombreamento artificial no bem estar de novilhas leiteiras criadas a pasto. 96.p, 2009.

MEYER, U.; STAHL,W; FLACHOWSKY,G. Invertigations on the water intake of growing bulls. Livertock Production Science, nº 103, p 186-191, 2006.

NÃ̃̃S, I.A. Princípios de conforto térmico na produção animal. São Paulo: Ícone, 1989.

PERERA, K. S.; GWADAUSKAS, F. C.; PEARSON, R.E.; BRUMCACK JUNIOR, T. B. Effect of season and stage of lactation on performance of Holstein. Journal Dairy Science, Champaign, v. 69, p. 228-236, 1986.

PEREIRA, J.C.C. Fundamentos de Bioclimatologia Aplicados à Produção Animal. Belo Horizonte: FEPMVZ, 2005. 195p.

PERISSINOTTO, M. Efeito da utilização de sistemas de climatização nos parâmetros fisiológicos do gado leiteiro. Engenharia Agrícola, Jaboticabal, v.26, n.3, p. 663-671, 2006. Disponível em http://www.readcube.com/articles/10.1590/S0100-69162006000300002. Acesso em: 20 Set. 2014.

PERISSINOTTO, M.et al. influência do ambiente na ingestão de água por vacas leiteiras. Revista Brasileira de Engenharia Agrícola e Ambiental, v.9, n.2, p.289-294, 2005.

PETERS, M.D.P.; SILVEIRA, I.D.B.; RODRUGUES, C.M. Interação humano e bovino de leite. Archives de Zootecnia, Córdoba, v. 55, p. 9-23, 2007.

PIRES, M.F.A.; CAMPOS, A.T. Conforto Animal para maior produção de leite, Viçosa-MG, CPT, 254p. 2008.

PIRES, M.F.A.; CARVALHO, M.M. Sombra natural em pastagem. Revista Gloria Rural. São Paulo, v.3, p.22-26, 2000.

PORTUGAL, J.A.B.; PIRES, M.F.A.; DURÃES, M.C. Efeito da temperatura ambiente e da umidade relativa do ar sobre a frequência de ingestão de alimentos e de água e de ruminação em vacas da raça Holandesa. Arq. Bras. Med. Vet. Zootec. vol.52 n.2 Belo Horizonte. 2000.

SILVA, R.S. Introdução à Bioclimatologia Animal. São Paulo: Nobel, 2000. 286p. 
TINÔCO, I. F. F. Avicultura industrial: novos conceitos de materiais, concepções e técnicas construtivas disponíveis para galpões avícolas brasileiros. Revista Brasileira de Ciência Avícola, v.3, p.1-26, 2001.

TITTO, E.A.L. Clima: Influencia na produção de leite. In: SIMPÓSIO BRASILEIRO DE AMBIÊNCIA NA PRODUÇÃO DE LEITE, Piracicaba, 1998. Anais... Piracicaba: FEALQ. 1998. p. 10-23. 